\title{
Functional Protective Coatings for Steel Architectural Construction Panels
}

\author{
Anna $V$. Ryabova ${ }^{1,}{ }^{*}$, Anna $Y u$. Fanda ${ }^{1}$, and Sergey $V$. Trofimov ${ }^{1}$ \\ ${ }^{1}$ Platov South-Russian State Polytechnic University (NPI), 346428, Prosveshcheniya street, 132, \\ Novocherkassk, Rostov region, Russia
}

\begin{abstract}
Currently, enameled steel products are becoming very popular in construction, since they have a number of valuable properties that noticeably distinguish enameled architectural and construction panels against the background of other facing building materials. Also, extremely urgent is the problem of obtaining glass enamel coatings for architectural and construction panels with high properties. In the work, glass-crystalline enamel coatings in the system $\mathrm{R}_{2} \mathrm{O}-\mathrm{RO}-\mathrm{B}_{2} \mathrm{O}_{3}-\mathrm{Al}_{2} \mathrm{O}_{3}-\mathrm{SiO}_{2}-\mathrm{TiO}_{2}-\mathrm{P}_{2} \mathrm{O}_{5}-$ $\mathrm{F}^{-}$were studied, the features of their formation on facing steel panels were revealed. The physicochemical and aesthetic-consumer properties of the developed enamel coatings have been investigated. The influence of the chemical composition of titanium-containing glass and the crystallization process on the whiteness index of white coating glass-crystalline enamels and the characteristic color shade was studied using a spectrophotometric method using an RGB color measurement model. This method made it possible to accurately determine the shades of the obtained glass-crystalline enamel coatings for steel.
\end{abstract}

\section{Introduction}

Nowadays, energy saving is becoming increasingly important. In countries located in northern latitudes, in particular, Russia, this problem is especially acute, since they are characterized by a rather harsh climate and large temperature drops. An enormous amount of heat and electrical energy is spent on heating structures in winter. Therefore, one of the priority solutions to this problem is the use of heat-insulating and resource-saving facing materials with high thermal insulation, as well as anti-corrosion and weather-resistant properties. The use of enamelled cladding steel panels increases the energy efficiency of the building, due to the accumulation of heat and cold, and reduces the cost of major repairs.

Energy efficient enamelled steel panels are one of the best options for cladding buildings. To reduce heat loss and increase noise insulation, composite facing enameled panels with an internal porous filler in the form of a cellular polymer material or foam glass are used. The use of such panels is possible not only for cladding residential buildings, but also for commercial and industrial real estate. These panels are resistant to high temperatures, while not emitting toxic substances; have high resistance to vandalism, namely abrasion, scratching and other mechanical influences; combine the strength of steel and the corrosion resistance

* Corresponding author: aannet20002006@yandex.ru 
of glass; quite easy to maintain, which allows them to be used also in metro stations, tunnels and underpasses.

Unlike other facing building materials, such as natural or artificial stone, porcelain stoneware, siding panels, facade plaster, polystyrene, clinker tiles and others, facing enameled steel panels have a number of advantages:

- enamel-based coating is resistant to various mechanical influences, due to its high hardness (according to the Mohs scale, enamel has a hardness of 6 [units]), unlike siding panels;

- in the event of antisocial behavior (vandalism), paints of various compositions, adhesives and varnishes can be applied to the enamel surface. Due to the chemical inertness of the enamel, almost any detergent can be used to clean enamel panels, which is especially important in tunnels and subways.

- unlike polystyrene, the enamel is absolutely moisture resistant, it perfectly protects the facade from the appearance of fungus and mold;

- The enamelled panel is highly resistant to UV radiation, which makes it immune to sunlight. Thanks to this property, the enamelled panel will not lose its original shine and color, and due to its high anti-corrosion resistance, it will retain its original appearance for several decades;

- Unlike porcelain stoneware and artificial stones, enamel panels have a low specific weight, which reduces the load on the foundation.

Since facing steel panels must have high resistance to atmospheric, chemical and mechanical influences, the most acceptable coating is the cover enamel used in the doublelayer enameling technology, belonging to the highest acid resistance classes.

Both in Russia and in other countries, problems of enameling steel products, incl. cladding steel panels, engaged in a large number of scientific staff. They carry out many studies in the field of formation of glass enamel coatings and the development of new deposition technologies $[1,2]$, synthesize new compositions of glass enamel coatings [3-5], and also study their properties [6-8].

Based on the foregoing, the purpose of this study is to study the structure and properties of glass-crystalline coatings for steel cladding panels.

\section{Theoretical part}

As the most suitable for the synthesis of glass enamel coatings in the technology of two-layer enameling, the aluminoborosilicate system $\mathrm{R}_{2} \mathrm{O}-\mathrm{RO}-\mathrm{B}_{2} \mathrm{O}_{3}-\mathrm{Al}_{2} \mathrm{O}_{3}-\mathrm{SiO}_{2}-\mathrm{TiO}_{2}-\mathrm{P}_{2} \mathrm{O}_{5}-\mathrm{F}^{-}$ was chosen, which can provide certain physicochemical and high aesthetic and consumer properties.

Thus, based on previous studies presented in table. 1, the chemical compositions of enamel coatings of three series have been developed - W (white), T (transparent), B (blue), containing 4 chemical compositions of the glass enamel coating. [9]

Table 1. Chemical compositions of enamel coatings

\begin{tabular}{|c|c|c|c|c|c|c|c|c|c|c|c|c|}
\hline \multirow{2}{*}{ 营 } & \multirow{2}{*}{ 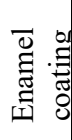 } & \multicolumn{11}{|c|}{ Oxide content, [mass \%] } \\
\hline & & $\mathrm{SiO}_{2}$ & $\mathrm{~B}_{2} \mathrm{O}_{3}$ & $\mathrm{Al}_{2} \mathrm{O}_{3}$ & $\mathrm{P}_{2} \mathrm{O}_{5}$ & $\mathrm{MgO}$ & $\mathrm{Na}_{2} \mathrm{O}$ & $\mathrm{K}_{2} \mathrm{O}$ & $\mathrm{TiO}_{2}$ & $\mathrm{CoO}$ & $\mathrm{CaO}$ & $\mathrm{F}^{-}$ \\
\hline \multirow{4}{*}{ W } & W1 & 44.0 & 13.0 & 4.0 & 3.57 & 1.2 & 11.5 & 6.68 & 16.0 & 0.05 & - & 3.5 \\
\hline & W2 & 42.0 & 15.0 & 4.0 & 3.57 & 1.2 & 11.5 & 6.68 & 16.0 & 0.05 & - & 3.5 \\
\hline & W3 & 42.0 & 13.0 & 4.0 & 3.57 & 1.2 & 13.5 & 6.68 & 16.0 & 0.05 & - & 3.5 \\
\hline & W4 & 42.0 & 13.0 & 4.0 & 3.57 & 1.2 & 11.5 & 6.68 & 18.0 & 0.05 & - & 3.5 \\
\hline
\end{tabular}




\begin{tabular}{|c|c|c|c|c|c|c|c|c|c|c|c|c|}
\hline \multirow{2}{*}{ 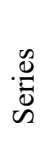 } & \multirow{2}{*}{ 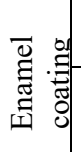 } & \multicolumn{11}{|c|}{ Oxide content, [mass \%] } \\
\hline & & $\mathrm{SiO}_{2}$ & $\mathrm{~B}_{2} \mathrm{O}_{3}$ & $\mathrm{Al}_{2} \mathrm{O}_{3}$ & $\mathrm{P}_{2} \mathrm{O}_{5}$ & $\mathrm{MgO}$ & $\mathrm{Na}_{2} \mathrm{O}$ & $\mathrm{K}_{2} \mathrm{O}$ & $\mathrm{TiO}_{2}$ & $\mathrm{CoO}$ & $\mathrm{CaO}$ & $\mathrm{F}^{-}$ \\
\hline \multirow{4}{*}{$\mathrm{T}$} & T1 & 49.0 & 14.0 & 11.3 & - & - & 15.0 & 1.2 & 5.0 & - & 4.5 & 5.0 \\
\hline & $\mathrm{T} 2$ & 49.0 & 11.0 & 11.3 & - & - & 18.0 & 1.2 & 5.0 & - & 4.5 & 5.0 \\
\hline & T3 & 49.0 & 17.0 & 8.3 & - & - & 15.0 & 1.2 & 5.0 & - & 4.5 & 5.0 \\
\hline & $\mathrm{T} 4$ & 52.0 & 11.0 & 8.3 & - & - & 18.0 & 1.2 & 5.0 & - & 4.5 & 5.0 \\
\hline \multirow{4}{*}{ B } & B1 & 49.5 & 11.0 & 10.6 & 2.2 & 1.5 & 17.0 & 1.2 & 2.5 & 1.5 & 3.0 & 5.0 \\
\hline & $\mathrm{B} 2$ & 49.5 & 15.0 & 5.6 & 2.2 & 1.5 & 18.0 & 1.2 & 2.5 & 1.5 & 3.0 & 5.0 \\
\hline & B3 & 49.5 & 15.0 & 10.6 & 2.2 & 1.5 & 13.0 & 1.2 & 2.5 & 1.5 & 3.0 & 5.0 \\
\hline & B4 & 51.5 & 15.0 & 5.6 & 2.2 & 1.5 & 16.0 & 1.2 & 2.5 & 1.5 & 3.0 & 5.0 \\
\hline
\end{tabular}

During the development of each enamel coating in each of the series, the content of oxides was changed, which have the greatest effect on the physicochemical and technical and operational properties of enamel coatings: in series $\mathrm{W}-\mathrm{SiO}_{2}, \mathrm{TiO}_{2}, \mathrm{~B}_{2} \mathrm{O}_{3}$ and $\mathrm{Na}_{2} \mathrm{O}$, in series $\mathrm{B}$ and $\mathrm{T}-\mathrm{SiO}_{2}, \mathrm{~B}_{2} \mathrm{O}_{3}, \mathrm{Al}_{2} \mathrm{O}_{3}$ and $\mathrm{Na}_{2} \mathrm{O}$. The percentage of the remaining oxides remained unchanged. [9-11]

\section{Experimental part}

After the synthesis and firing of enamel coatings, their visual analysis was carried out using an electronic optical microscope Bresser Duolux, the results of which are shown in Figure 1, in order to identify the optimal quality of the synthesized enamel compositions. The analysis showed that samples W3 and W4 have segregation layers on the surface in the form of different color shades, namely: yellow and white. The size of these defects varies from 50 to $250[\mathrm{~nm}]$. Also, the presented samples have an unevenly crystallized surface with defects. This is due to the fact that during the liquation of titanosilicate melts, the formation of highsilica and low-silica melts occurs, which can have a significant effect on the chemical resistance of the enamel coating. [12]

Coatings W1 and W2 are characterized by a smoother surface and fewer defects than coatings of similar composition. Samples of the T series, namely, compositions T2 and T3, have a smooth surface with high gloss and black color. The black color of the sample is achieved with a transparent cover enamel, which shines through the base enamel. T1 coatings have a number of burnouts over the entire surface, while T4 has an inhomogeneous surface with a low gloss index. Evaluation of the appearance of samples of the B series revealed the optimal compositions B1 and B3, which have high gloss values, as well as a uniform surface of a saturated blue color.

It can be seen from the data obtained that the synthesized coatings in the system $\mathrm{R}_{2} \mathrm{O}$ $\mathrm{RO}-\mathrm{B}_{2} \mathrm{O}_{3}-\mathrm{Al}_{2} \mathrm{O}_{3}-\mathrm{SiO}_{2}-\mathrm{TiO}_{2}-\mathrm{P}_{2} \mathrm{O}_{5}-\mathrm{F}^{-}$, namely compositions $\mathrm{W} 3$ and $\mathrm{W} 4$, are characterized by a sufficiently high coefficient of diffuse reflection, however, upon visual inspection, the samples have a yellowish tint. 


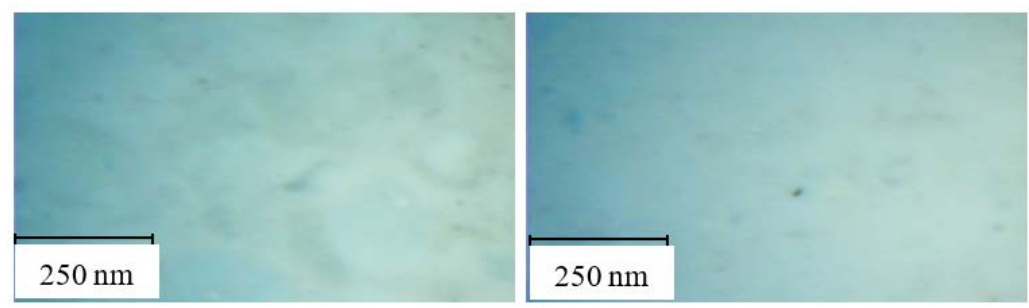

a)

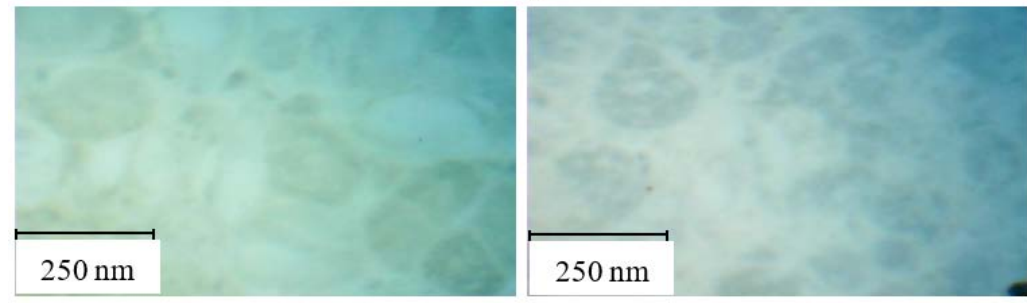

b)

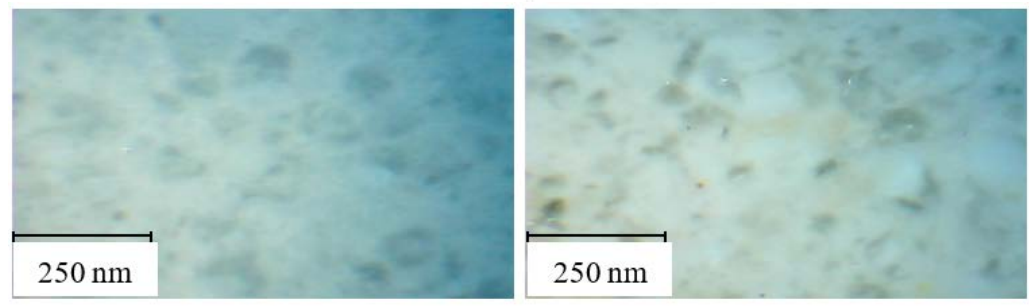

c)

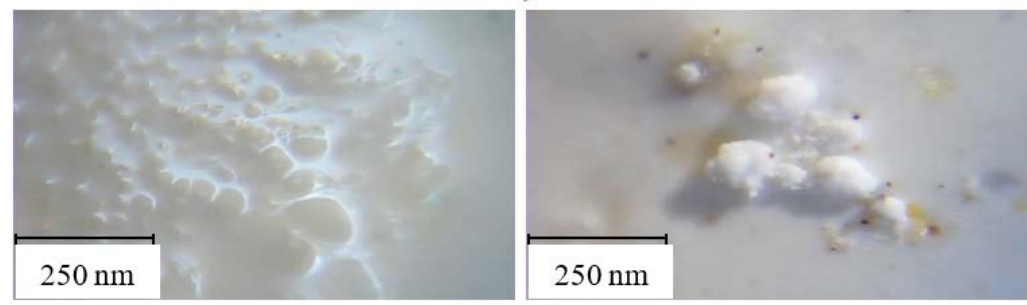

d)

Fig. 1. Microscopic analysis of white coatings using an electron microscope BresserDuolux (10x): a) series B1; b) B2 series; c) series B3; d) B4 series

In all GOSTs concerning the production of enameled products, including GOST R 525692006 «Frit. Technical conditions», the method by which it is necessary to determine the brightness index is not indicated. In the latter, it is only mentioned that the value of the brightness coefficient should be at least 75 [\%], therefore, the method for assessing the whiteness of the glass enamel coating by the diffuse reflectance coefficient and the brightness index does not take into account the color shade. Therefore, to determine the shades of white glass enamel coating, a spectrophotometric method was proposed using the RGB color measurement model. In accordance with it, a color shade is characterized by certain light wavelengths and color coordinates.

For a correct assessment of the color characteristics of coatings, reference optical characteristics were introduced for white enamel coatings with various shades, the numerical values of which are presented in Table 2, and the graphical data in Table 3. 
In order to establish the exact color shades of the resulting enamel coatings, spectrophotometric analysis was carried out, which showed that some coatings have a certain wavelength in the range fixed for light yellow, which is $575-580$ [nm]. Analysis of the data presented in Tables 2 and 3 based on the dominant wavelength allows very accurate determination of the color shades of the resulting coatings. [13, 14]

Table 2. Spectrophotometric color characteristics

\begin{tabular}{|c|c|c|c|c|c|c|c|c|c|}
\hline \multirow{3}{*}{$\begin{array}{l}\text { № } \\
\mathrm{p} / \mathrm{p}\end{array}$} & \multirow{3}{*}{$\begin{array}{l}\text { Reference } \\
\text { colors }\end{array}$} & \multicolumn{5}{|c|}{ Color characteristics } & \multicolumn{3}{|c|}{ Color coordinates } \\
\hline & & \multirow{2}{*}{ Color } & \multirow{2}{*}{$\begin{array}{l}\text { Wavelength, } \\
\lambda, \mathrm{nm}\end{array}$} & \multicolumn{3}{|c|}{ RGB values } & \multirow{2}{*}{$\mathrm{X}$} & \multirow{2}{*}{$\mathrm{Y}$} & \multirow{2}{*}{ Z } \\
\hline & & & & red & green & blue & & & \\
\hline 1 & White & & $380-760$ & 255 & 255 & 255 & 0.24 & 0.25 & 0.24 \\
\hline 2 & White-blue & & $465-482$ & 230 & 233 & 221 & 0.22 & 0.29 & 0.24 \\
\hline 3 & $\begin{array}{l}\text { White- } \\
\text { yellow }\end{array}$ & & $575-580$ & 222 & 229 & 237 & 0.22 & 0.23 & 0.26 \\
\hline 4 & White-gray & & $380-760$ & 234 & 231 & 176 & 0.23 & 0.23 & 0.17 \\
\hline
\end{tabular}

Table 3. Graphical data of spectrophotometry

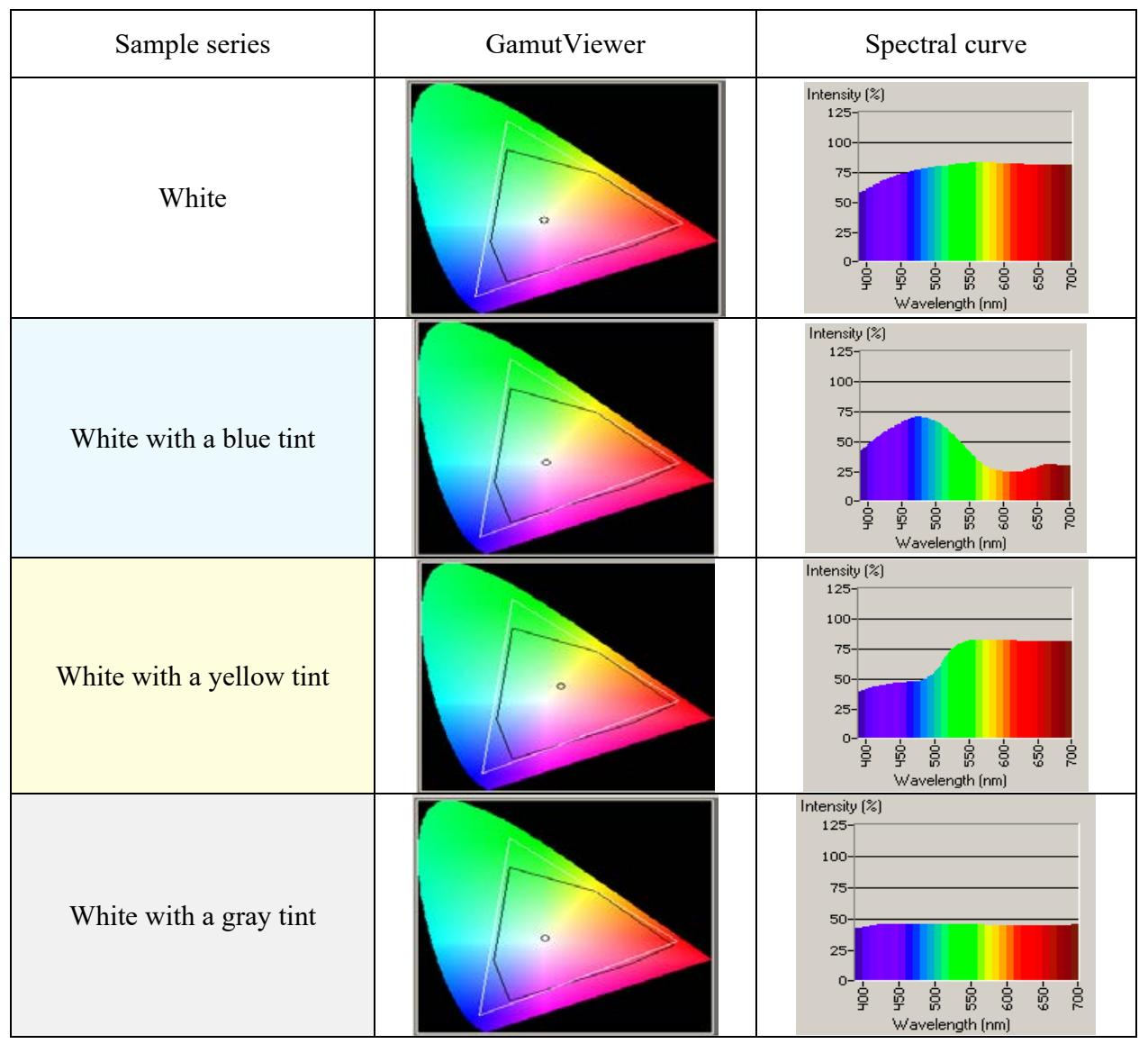


In order to identify the reasons for the production of white coatings with different shades, an analysis of the microstructure of the synthesized enamels was carried out (Figure 2), which made it possible to establish that the compositions W3 and W4 have a characteristic yellow tint, which is found only in the surface layer of enamel coatings, which indicates the transition of anatase into rutile starting from the surface layers of the coating. Thus, the chemical compositions $\mathrm{W} 3$ and $\mathrm{W} 4$ of the synthesized glass matrices in the $\mathrm{R}_{2} \mathrm{O}-\mathrm{RO}-\mathrm{B}_{2} \mathrm{O}_{3}-\mathrm{Al}_{2} \mathrm{O}_{3}-$ $\mathrm{SiO}_{2}-\mathrm{TiO}_{2}-\mathrm{P}_{2} \mathrm{O}_{5}-\mathrm{F}^{-}$system do not provide uniform fine-crystalline crystallization and color uniformity of the surface, in contrast to compositions W1 and W2.

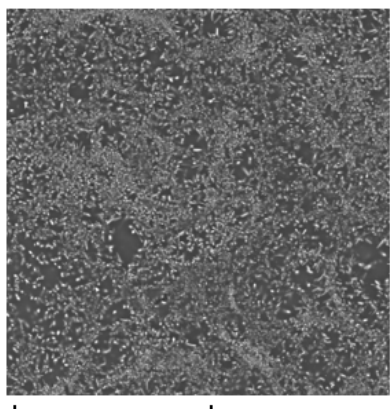

$500 \mathrm{~nm}$

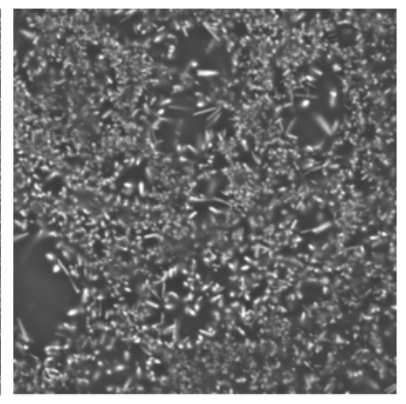

$200 \mathrm{~nm}$

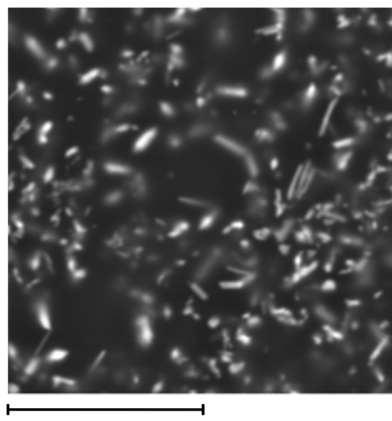

$100 \mathrm{~nm}$

Fig. 2. Micrographs of the structure of synthesized enamels

In order to establish the phase composition of the synthesized white coatings, compositions W3 and W4, X-ray studies of their structure were carried out, the results of which are shown in Figure 3.

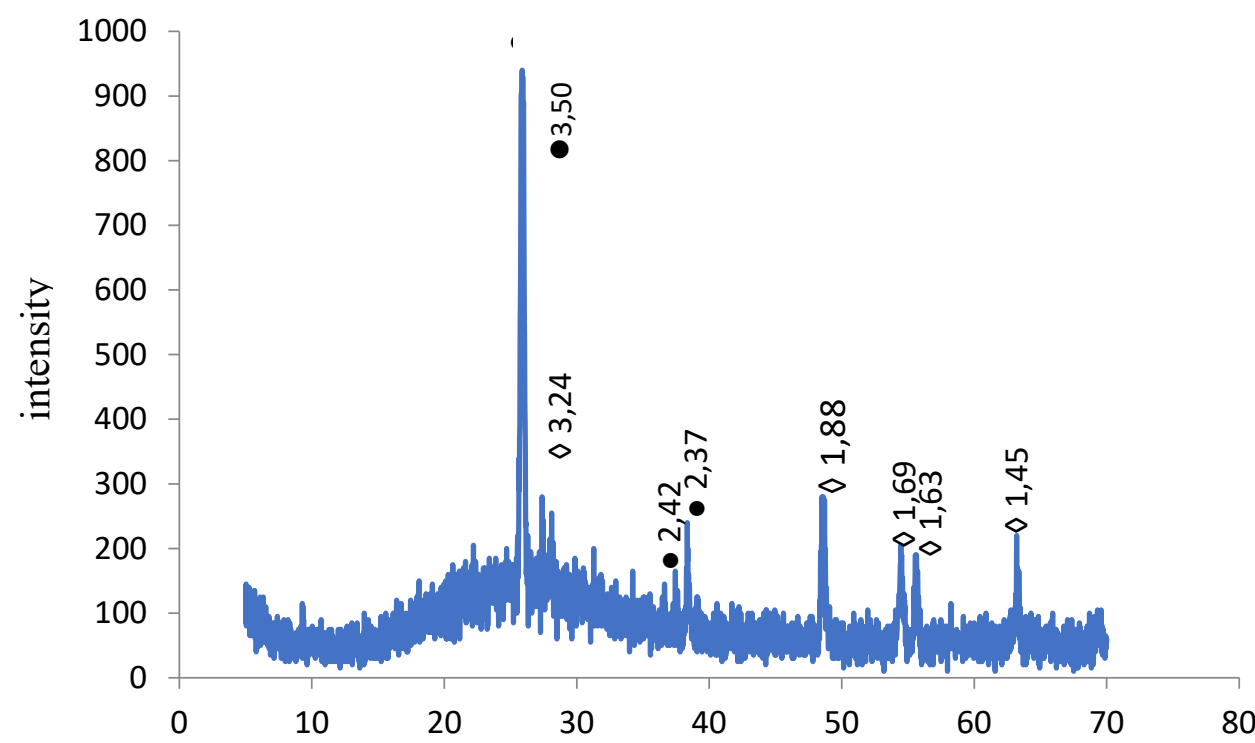

Fig. 3. X-ray diffraction pattern of experienced glass-crystalline enamel coatings of compositions W3 and W4 with a yellow tint $(\bullet$-anatase; $\diamond$-rutil) 
Analysis of the diffraction pattern made it possible to establish that the crystalline phase in the synthesized coatings is represented by titanium dioxide in the form of both anatase and rutile. However, the highest scattering intensity corresponds to anatase (interplanar distance $3.50\left[\mathrm{~A}^{\circ}\right]$ ) and is 1000 . While for true white enamels with anatase form of damping, the intensity reaches 2200. Rutile crystals are also present in a significant amount, which gives glass-crystalline coatings have a yellowish tint. This indicates an insufficiently intensive crystallization process during coating firing.

\section{Results and discussion}

The analysis of the obtained experimental data made it possible to establish that high indicators of whiteness, color and gloss of coatings are provided by the structural and morphological features of glass enamel having a glass-crystalline structure and containing a crystalline phase represented by titanium dioxide and a glassy phase represented by alkalialuminosilicate glass. Thus, the synthesized glass-crystalline enamel coatings, compositions W1 and W2, obtained by the technology, including the stages of preliminary chemical treatment of the steel used, applying to it and firing ground and cover enamels, have good indicators of aesthetic, consumer and structural properties, which ensures their possible use. as protective coatings for cladding steel panels.

These coatings have a fairly uniform color tone and are characterized by high aesthetic, consumer and technical and operational properties; they can also be used in mass production to protect various buildings and structures. The resulting colors make it possible to expand the scope of application of enamel coatings, improve their aesthetic and consumer properties. The chemical compositions $\mathrm{W} 3$ and $\mathrm{W} 4$ of the synthesized glass matrices in the system $\mathrm{R}_{2} \mathrm{O}$ $\mathrm{RO}-\mathrm{B}_{2} \mathrm{O}_{3}-\mathrm{Al}_{2} \mathrm{O}_{3}-\mathrm{SiO}_{2}-\mathrm{TiO}_{2}-\mathrm{P}_{2} \mathrm{O}_{5}-\mathrm{F}^{-}$do not provide uniform fine-crystalline crystallization and color uniformity of the surface, in contrast to compositions W1 and W2, which indicates the transition of anatase to rutile. starting from the surface layers of the coating. Thus, further studies should be carried out in the direction of creating conditions under which the crystals of titanium dioxide in the anatase modification will stabilize, which will prevent excessive growth of its crystals and further transition to rutile.

\section{Conclusions}

Thus, in the course of the work, glass-crystalline enamel coatings in the system $\mathrm{R}_{2} \mathrm{O}-\mathrm{RO}$ $\mathrm{B}_{2} \mathrm{O}_{3}-\mathrm{Al}_{2} \mathrm{O}_{3}-\mathrm{SiO}_{2}-\mathrm{TiO}_{2}-\mathrm{P}_{2} \mathrm{O}_{5}-\mathrm{F}^{-}$were studied, the features of their formation on facing steel panels were revealed. The influence of the chemical composition of titanium-containing glass and the crystallization process on the whiteness index of white coating glass-crystalline enamels and the characteristic color shade was studied using a spectrophotometric method using an RGB color measurement model. This method made it possible to accurately determine the shades of the obtained glass-crystalline enamel coatings for steel.

This work was supported by the RFBR grant No. 20-33-90223 «Development of technology for energysaving steel anti-vandal architectural and construction panels with an external glass enamel coating and internal heat-insulating aggregate».

\section{References}

1. Jiming Gao, Yuqing Bao, David T.Gawne. Microporosity and delamination mechanisms in thermally sprayed borosilicate glass coatings// Surface and Coatings Technology. 2016. V. 304. pp. 195-202. 
2. O.V. Shalygina L.L. Bragina. No-undercoat enamels with a complex bonding catalyst for PUESTA technology // Glass and Ceramics. 2011. V. 67. I. 9-10. pp. 328-330.

3. S.P. Rodtsevich, V.V. Tavgen', T.S. Minkevich. Effect of alkali metal oxides on the properties of titanium containing glass enamels // Glass and Ceramics. 2007, V. 64. I. 7-8. pp. 244-246.

4. O.R. Lazutkina, A.K. Kazak, E.A. Pushkareva, I.F. Khairislamova. Low-temperature covering enamels for steel and aluminum // Glass and Ceramics. 2008. V. 65. I. 1-2. pp. 63-64.

5. Stefano Rossi, Caterina Zanella, Ryan Sommerhuber. Influence of mill additives on vitreous enamel properties// Materials \& Design. 2014. V. 55. pp. 880-887.

6. O.R. Lazutkina, N.B. Mullagalieva, A.K. Kazak. Service Parameters of Enamels for Pipes // Glass and Ceramics. 2005. V. 62. I. 7-8. pp. 226-227.

7. Steel facing enameled panels for construction purposes / Fanda A.Yu.; Ryabova A.V.; // Student scientific spring - 2020: materials of regional scientific and technical. conf. (competition of scientific and technical works) of students, graduate students and young scientists of universities Rost. region, Novocherkassk, May 13-14, 2020 / Yuzh.-Ros. state polytechnic un-t (NPI) them. M.I. Platova - Novocherkassk: YRSPU (NPI), 2020. - pp. 98-99.

8. Ken Chen, Minghui Chen et al. Simulating sulfuric acid dew point corrosion of enamels with different contents of silica // Corrosion Science. 2017. V. 127. pp. 201-212.

9. Bragina L.L. and other Technology of enamel and protective coatings: Textbook. allowance / Ed. L.L. Bragina, A.P. Zubekhin. - Kharkiv: NTU "KhPI"; Novocherkassk: YURSTU (NPI), 2003. - P. 484.

10. Crystallization Peculiarities of White Glass-Enamel Coatings for SteelProducts / Klimova L.V.; Ryabova A.V., Fanda A.Yu. // Materials Science Forum - 2019. - Vol. 945: International Multi-Conference on Industrial Engineering and Modern technologies (FarEastCon2018), Vladivostok, Russia jn 2-4 October. 2018 - pp. $665-$ 669.

11. Synthesis and Investigation of White Glass-Ceramic Enamel Coatings for Steel Products / Ryabova A.V.; Yatsenko E.A., Klimova L.V., Filatova E.V., Velichko A. Yu.; // Glass Physics and Chemistry - 2017. - Vol. 43, №1. - pp. 34-42.

12. Influence of raw materials on glass formation and crystallization of white enamel coatings for steel products / Ryabova A.V.; // Research results - 2015: materials of the 1 st National Conf. teaching staff and scientific. Workers of YRSPU (NPI) / Yuzh.-Ros. state polytechnic un-t (NPI) them. M.I. Platova - Novocherkassk: YRSTU (NPI), 2015. - pp. 104-106.

13. Study of spectrophotometric characteristics of white glass-crystalline enamel coatings [Electronic resource] / Ryabova A.V., Klimova L.V., Velichko A.Yu., Horoshavina V.V. // Engineering Bulletin of Don: [electron. zhurn.] - 2016. - No. 4. - Access mode: http://www.ivdon.ru/ru/magazine/archive/n4y2016/3878.

14. CIE Lab system for assessing the shades of white glass-crystalline enamel coatings / Velichko A.Yu.; Fanda K.A., Ryabova A.V.; // Intellectual and scientific potential of the XXI century - collection of articles. Art. Int. scientific-practical Conf., Kazan, December 20. 2016: at 6 o'clock / Scientific-ed. center. Aeterna - Ufa: Aeterna, 2016. - Part 4. - pp. 42-44. 